\title{
Infectious etiologies of genital elephantiasis outside of filariasis endemic regions: a case report
}

\author{
Youssef Kharbach* ${ }^{*}$, Zakaria Bakali Issaoui, Youssef Retal and Abdelhak Khallouk
}

\begin{abstract}
Background: Isolated genital elephantiasis outside filariasis endemic tropical and subtropical regions is rare and presents a diagnostic and therapeutic challenge. Serologic and radiographic investigation must be undertaken to exclude reversible causes of genital elephantiasis.
\end{abstract}

Case presentation: Authors report herein the case of a 58-year-old patient with chronic penile and scrotal elephantiasis. He had a history of untreated urethritis and an endoscopic urethrotomy for urethra stricture three years ago. Serological test for chlamydiosis was positive. Retrograde urethrocystography demonstrated a bulbar urethra stricture. The patient spectacularly and completely improved after endoscopic urethrotomy and long-term doxycycline.

Conclusions: Early treatment of sexual transmitted infections such as chlamydiosis is important to prevent the evolution of penoscrotal elephantiasis and to avoid surgical procedures.

Keywords: Elephantiasis, Lymphedema, Filariasis, Scrotum

\section{Background}

Genital elephantiasis is uncommon outside of filariasis endemic regions. It is caused by pathological process affecting the lymph vessels and nodes that leads to lymphatic fluid retention in subcutaneous tissues. It is a very debilitating disease, which causes problems with hygiene, difficulties with urination, loss of copulation function and problems while walking [1].

The etiological diagnosis of genital chronic elephantiasis, outside of filariasis endemic regions, is a very challenging task. The etiologies may be congenital and are due to malformation of lymphatic vessels, or acquired, induced by genital infection (lymphogranuloma venereum) [2], recurrent inflammation [3], neoplasm, irradiation, lymph node dissection, continuous ambulatory peritoneal dialysis and idiopathic disorders $[1,2,4]$. Conservative measures may be helpful depending on the

*Correspondence: ykharbach@uae.ac.ma

Urology Department, Tangier University Hospital, Faculty of Medicine,

Abdelmalek Essaâdi University, 90000 Tangier, Morocco underlying cause and stage of the disease. However, it is necessary to emphasize that the most effective treatment is excision of the elephantoid tissues and reconstruction of the defect.

We analyzed the clinical data and reviewed published literature. We performed a bibliographic search on different databases: PubMed, ScienceDirect using the following keywords and MeSH: "Elephantiasis," "Lymphedema," "Filariasis" and "Scrotum."

\section{Case presentation}

A 58-year-old male presented to the urologist with a 6-month history of a gradually enlarging scrotum and dysuria. The patient had no history of irradiation or travel to filariasis endemic regions. He had history of inadequately treated episodes of urethritis. He had been treated for urethral stricture 3 years ago when he presented with dysuria of one-year duration. No other medical problems were found, and he had not been experiencing significant disability. The physical examination revealed a grossly enlarged scrotum (Fig. 1) with normal 
inferior limbs. The scrotal skin was hard, thickened and massively edematous. The testes and cord structures were unidentifiable. Inguinal examination had not revealed any adenopathy. Ultrasonography showed the presence of two normal testes. Serological test for chlamydiosis (Elisa anti-chlamydia trachomatis, IgG) was positive. The recent retrograde urethrocystography demonstrated a bulbar urethra stricture and a multiple bladder diverticula bladder (Fig. 2).

An endoscopic urethrotomy had been performed on the patient, and a 6-week doxycycline treatment was conducted. The elephantiasis disappeared after treatment (Fig. 3). A surgical diverticulectomy will be performed in 3 months.

Considering the history of urethritis, serological findings and the clinical improvement we believe that chronic untreated Chlamydia trachomatis infection is the etiology of the genital elephantiasis of our patient.

\section{Discussion}

The genital elephantiasis is more commonly encountered in tropical and subtropical countries like India [5]. These regions are endemic in filariasis, and lymphatic alterations are mainly due to the infestation by Wuchereria bancrofti. Almost $20 \%$ of male population can be affected [5].

Outside of these regions, genital elephantiasis represents a diagnostic challenge. McDougal made a classification of lymphedema of external genitalia which is based on factors such as congenital versus acquired, sporadic

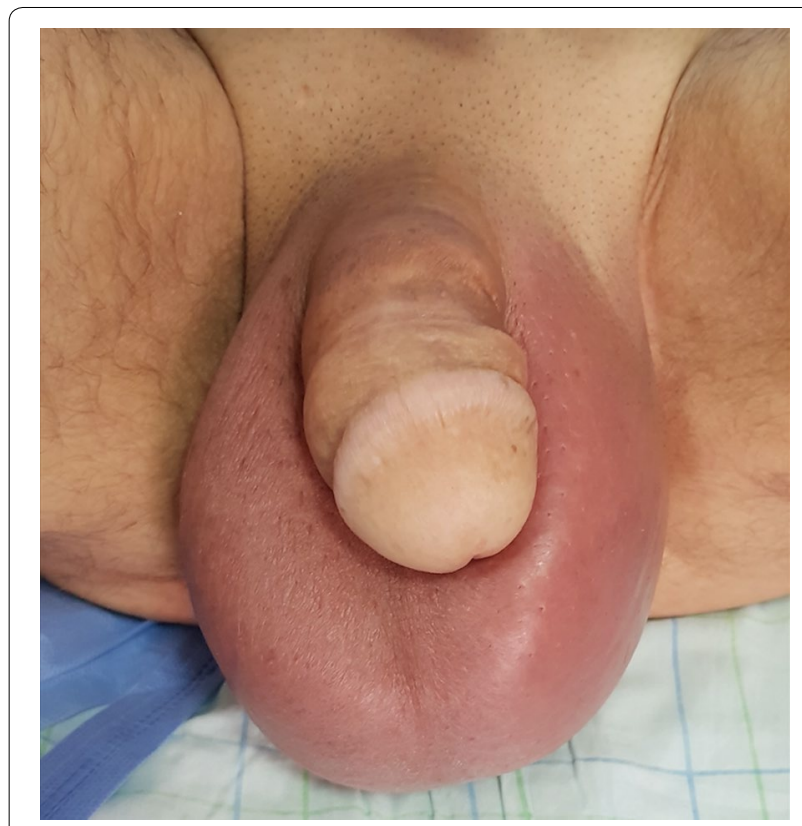

Fig. 1 Scrotal lymphedema

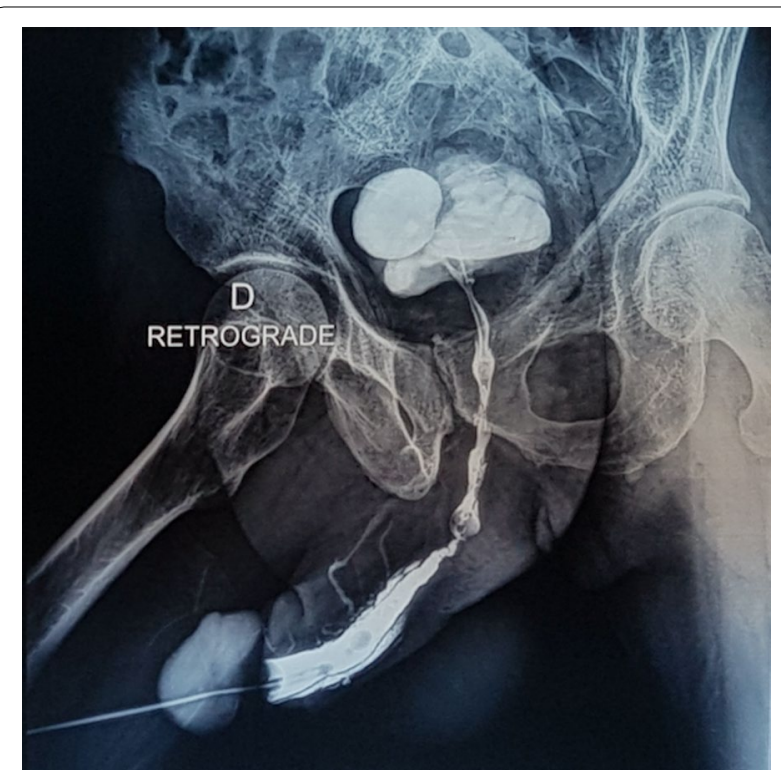

Fig. 2 Retrograde urethrocystography showing a bulbar urethra stricture and a multidiverticular elevated bladder

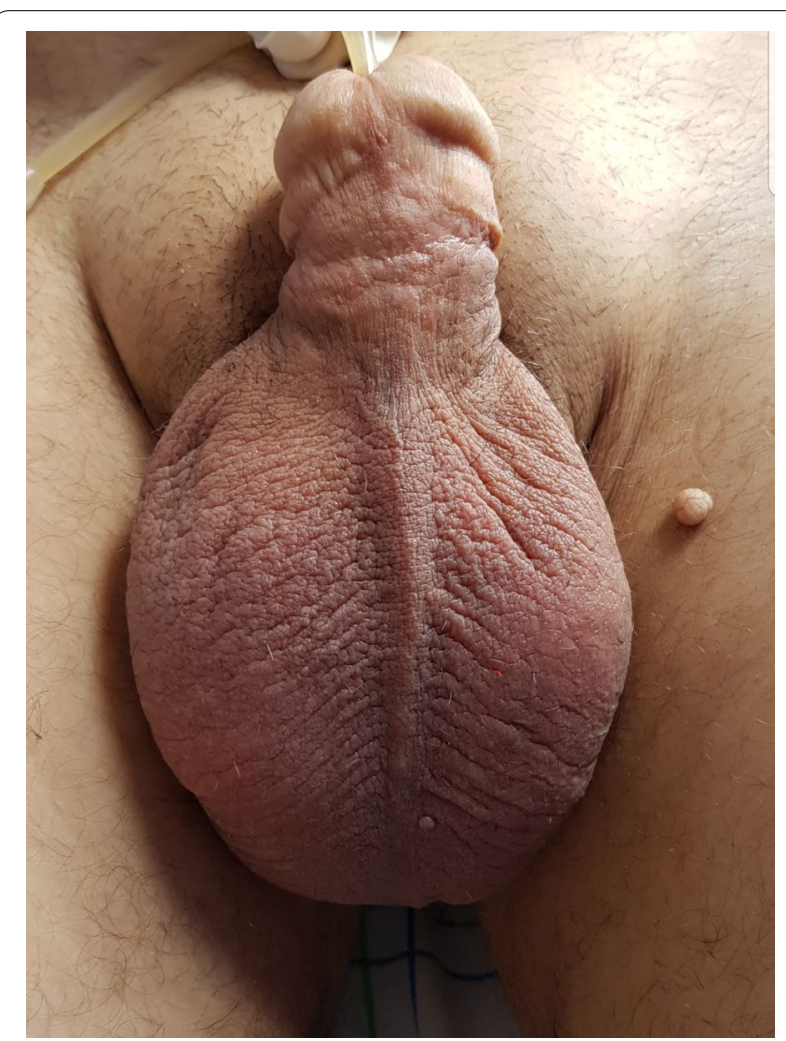

Fig. 3 Scrotum after 3 weeks of doxycycline treatment 
versus inherited and age of onset [4]. Identifying the underlying etiology is mandatory because, depending on the cause of the penoscrotal edema, conservative measures such as medical treatment against lymphogranuloma venereum and bancroftian filariasis are helpful and can cure early stages of the disease [6].

In non-endemic countries with filariasis, the neoplastic and congenital origins must be suspected first. Otherwise, the genital elephantiasis is idiopathic or due to infectious diseases. Indeed, the causative agent of lymphogranuloma venereum (LGV), Chlamydia trachomatis serovar L1-L3, is a lymphotrophic organism which leads to the development of severe alterations in lymphatic channels. Therefore, LGV can be complicated by penoscrotal elephantiasis $[2,7]$, and $4 \%$ of patients with LGV have been reported to develop penile and scrotal elephantiasis as a late complication [8]. Early anti-infectious therapy with doxycycline given orally is important to prevent genital elephantiasis in these cases [1].

Donovanosis, another sexually transmitted infection due to Klebsiella granulomatis, can generate in 5\% of patients elephantiasis $[9,10]$. Donovanosis should be treated with azithromycin or trimethoprim-sulfamethoxazole combination for a minimum of three weeks

Syphilis should also be suspected as a differential diagnosis especially in patients with systemic symptoms accompanied by penoscrotal elephantiasis with a history of genital ulcer [11].

Other inflammatory or infectious diseases are described to cause genital lymphedema such as: recurrent streptococcus infections with resultant post inflammatory changes $[2,12]$ and hidradenitis suppurative which is a chronic recurrent inflammation of apocrine sweat glands [3]. However, although performing thorough serologic and radiographic evaluation, in many cases no etiology is identified and the elephantiasis is classified as idiopathic.

For advanced stages surgery remains the only solution. Complete excision of all lymphedematous tissue, with preservation of the testes, spermatic cord and the penis, followed by plastic penoscrotal reconstruction is appropriate to avoid recurrence.

\section{Conclusions}

Scrotal elephantiasis is uncommon outside of filariasis endemic regions. Serologic and radiographic investigation must be undertaken to exclude reversible causes of genital elephantiasis. Early treatment of sexual transmitted infections such as LGV and donovanosis is important to prevent the evolution to penoscrotal elephantiasis. However, in extensive disease, the surgical treatment is mandatory.

\section{Acknowledgements}

Not applicable.

\section{Authors' contributions}

YK and AK were involved in concept, design, supervision, processing, writing the manuscript and critical analysis. AK revised the manuscript. ZBI and YR were involved in data acquisition. All authors read and approved the final manuscript.

\section{Funding}

None

\section{Availability of data and materials}

The datasets generated during and/or analyzed during the current study are available from the corresponding author on reasonable request.

Ethics approval and consent to participate

The Ethics Committee of Tangier Medical School evaluated and approved our case report.

\section{Consent for publication}

Written informed consent was obtained from the patient for publication of this case report and any accompanying images.

\section{Competing of interests}

The authors report no competing personal or financial interest related to this work.

Received: 11 October 2019 Accepted: 24 June 2020

Published online: 05 October 2020

\section{References}

1. Kuepper D (2005) Giant scrotal elephantiasis. Urology 65:389

2. Nelson AR, Alberts GL, King LE (2003) Penile and scrotal elephantiasis caused by indolent Chlamydia trachomatis infection. Urology 61:224

3. Konety BR, Cooper T, Flood HD, Futrell JW (1996) Scrotal elephantiasis associated with hidradenitis suppurative. Plast Reconstr Surg 97:1243-1245

4. McDougal SW (2003) Lymphadenoma of external genitalia. J Urol 170:711-716

5. Dandapat MC, Mohapatro SK (1985) Elephantiasis of the penis and scrotum: a review of 350 cases. Am J Surg 149:686-690

6. Hoerauf A, Mnad S, Fisher K et al (2003) Doxycycline as novel strategy against bancroftian filariasis-depletion of wolbachia endosymbiots from wuchereria bancrofti and stop of microfilaria production. Med Microbiol Immunol 192:211-216

7. Sevensky LD, Lambierto A, Casco R, Woscoff A (1997) Lymphogranuloma venereum: tertiary stage. Int J Dermatol 36:47-49

8. Rothenberg RB (1999) Lymphogranuloma venereum. In: Freedberg IM, Eisen AZ, Wolff K et al (eds) Fitzpatrick's dermatology in general medicine. McGraw-Hill, New York, pp 2591-2594

9. Sehgal VN, Jain MK, Sharma VK (1987) Pseudoelephantiasis induced by donovanosis. Genitourin Med 63:54-56

10. Gupta S, Ajith C, Kanwar AJ, Sehgal VN, Kumar B, Mete U (2006) Genital elephantiasis and sexually transmitted infections-revisited. Int J STD AIDS 17:157-165

11. Stamatiou KN, Karakos C, Karanasiou V, Papadimitriou V, Sofras F (2007) Syphilitic Elephantiasis of Penis and Scrotum. Urol J 4:245-247

12. Porter W, Bunker C (2001) Chronic penile lymphedema: a report of six cases. Arch Dermatol 137:1108-1110

\section{Publisher's Note}

Springer Nature remains neutral with regard to jurisdictional claims in published maps and institutional affiliations. 